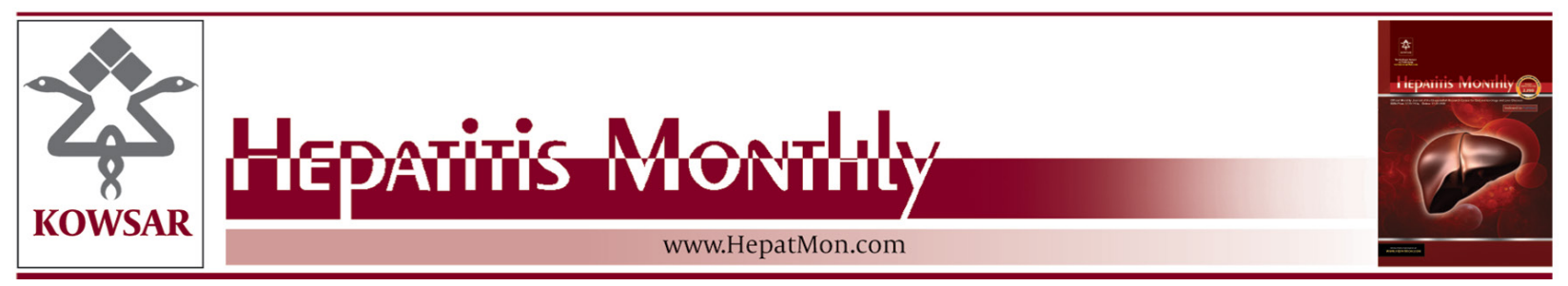

\title{
Patient-to-Patient Transmission of Hepatitis C at Iranian Thalassemia Cent- ers Shown by Genetic Characterization of Viral Strains
}

\author{
Katayoun Samimi-Rad ${ }^{1,{ }^{*},}$, Freshteh Asgari ${ }^{2}$, Mohsen Nasiritoosi ${ }^{3}$, Abdoulreza Esteghamati ${ }^{4}$, \\ Azar Azarkeyvan ${ }^{5}$, Seyedeh Masoomeh Eslami ${ }^{6}$, Farhad Zamani ${ }^{7}$, Lars Magnius ${ }^{8}$, Seyed \\ Moayed Alavian ${ }^{8}$, Heléne Norder ${ }^{9}$ \\ ${ }^{1}$ Department of Virology, School of Public Health, Tehran University of Medical Sciences, Tehran, IR Iran \\ ${ }^{2}$ Center for Disease Control, Deputy of Health, Ministry of Health and Medical Education, Tehran, IR Iran \\ ${ }^{3}$ Department of Internal Medicine, Gastroenterology and Hepatology Section, Tehran University of Medical Sciences, Tehran, IR Iran \\ ${ }^{4}$ Department of Pediatric, Tehran University of Medical Sciences, Tehran, IR Iran \\ ${ }^{5}$ Iranian Blood Transfusion Organization (IBTO), Thalassemia Center, Tehran, IR Iran \\ ${ }^{6}$ Gastrointestinal and Liver Disease Research Center, Firoozgar Hospital, Tehran University of Medical Sciences, Tehran, IR Iran \\ ${ }^{7}$ Department of Microbiology, Tumor and Cell Biology (MTC), Karolinska Institute, Solna, Sweden \\ ${ }^{8}$ Research Center for Gastroenterology and Liver Disease, Baqiatallah University of Medical Sciences, Tehran, IR Iran \\ ${ }^{9}$ Department of Infectious Diseases, University of Gothenburg, Gothenburg, Sweden \\ * Corresponding author: Katayoun Samimi-Rad, Department of Virology, School of Public Health, Tehran University of Medical Sciences, P. O. Box: 6446, \\ Tehran, IR Iran. Tel.: +98-2188950595, Fax: +98-2166462267, E-mail: ksamimirad@sina.tums.ac.ir.
}

\section{A B S T R A C T}

Background: Hepatitis $\mathrm{C}$ is prevalent among thalassemia patients in Iran. It is mainly transfusion mediated, in particular among patients treated before 1996 when blood screening was introduced.

Objectives: The current study aimed to investigate why patients still seroconvert to anti-HCV in Iranian thalassemia centers.

Patients and Methods: During 2006-2007 sera were sampled from 217 anti-HCV positive thalassemia patients at nine thalassemia centers in Tehran and Amol city, where 34 (16\%) patients had been infected after 1996. The HCV subtype could be determined by sequencing and phylogenetic analysis of partial NS5B and/or 5'NCR-core region in 130 strains.

Results: $1 \mathrm{a}$ (53\%) was predominant followed by $3 \mathrm{a}(30 \%), 1 \mathrm{~b}(15 \%)$, and one strain each of $2 \mathrm{k}$, 3k and 4a. Phylogenetic analysis revealed 19 clades with up to five strains diverging with less than six nucleotides from each other within subtypes la and 3a. Strains in seven clades were from nine patients infected between 1999 and 2005 and similar to strains from eight patients infected before 1996, indicating ongoing transmission at the centers. Further epidemiological investigation revealed that 28 patients infected with strains within the same clade had frequently been transfused at the same shift sitting on the same bed. An additional eight patients with related strains had frequently been transfused simultaneously in the same room.

Conclusions: The results suggest nosocomial transmission at these thalassemia centers both before and after the introduction of blood screening. Further training of staff and strict adherence to preventive measures are thus essential to reduce the incidence of new HCV infections.

Keywords: Hepatitis C; Thalassemia; Iran

Copyright ( 2013, Kowsar Corp.; Published by Kowsar Corp.

-Article type: Research Article; Received: 12 Aug 2012, Revised: 10 Nov 2012, Accepted: 12 Nov 2012; DOI: 10.5812/hepatmon.7699

Implication for health policy/practice/research/medical education:

This is the first report on the nosocomial HCV transmission at Iranian thalassemia centers. This study highly recommends adherence to protective measures in order to reduce the risk of acquiring HCV through nosocomial transmission at these centers.

PPlease cite this paper as:

Samimi-Rad K, Asgari F, Nasiritoosi M, Esteghamati A, Azarkeyvan A, Eslami SM, Zamani F, Magnius L, Alavian SM, Norder H. Patientto-Patient Transmission of Hepatitis C at Iranian Thalassemia Centers Shown by Genetic Characterization of Viral Strains. Hepat Mon. 2013;13(1):e7699. DOI: 10.5812/hepatmon.7699

Copyright @ 2013, Kowsar Corp;; Published by Kowsar Corp.

This is an Open Access article distributed under the terms of the Creative Commons Attribution License (http://creativecommons.org/licenses/by/3.0), which permits unrestricted use, distribution, and reproduction in any medium, provided the original work is properly cited. 


\section{Background}

Thalassemia major and thalassemia intermedia are both common transfusion dependent anemias in Iran. There are around 18000 known thalassemia patients in the country (1). Reports from different regions of Iran estimate that $18 \%$ of the thalassemia patients are positive for anti-HCV (1-3), which is far higher than the positivity rate of $0.5 \%$ found in the general Iranian population (4). Most of the thalassemia patients live in Tehran ( $\mathrm{n}=$ $2,850)$ and Mazandaran ( $\mathrm{n}=2,880)$ provinces. Transfusion of unscreened blood was previously the main risk factor for HCV infection in thalassemia patients, but this risk was reduced after 1996 when screening for anti-HCV was introduced at all blood banks in Iran $(5,6)$. In 2005 the Ministry of Health and Medical education implemented a national plan to decrease the rate of infection in thalassemia patients by offering free anti-HCV testing and anti-viral treatment to those found positive. This supplementary strategy has decreased the number of newly infected, although new infections still occur at low rate. This may be due to inaccurate blood screening or by transfusion of blood collected from hepatitis $\mathrm{C}$ infected donors during the window period before anti-HCV appears. Other nosocomial exposures may also play a role in HCV transmissions. Sequence analysis of the infecting HCV strains is now a powerful tool to trace infectious sources and thereby also transmission routes (6).

\section{Objectives}

The current study aimed to characterize HCV strains from patients at thalassemia centers in Tehran in Tehran province and in Amol City in Mazandaran province to investigate possible nosocomial transmission at these centers.

\section{Patients and Methods}

\subsection{Study Population}

Two hundred seventeen thalassemia patients positive for anti-HCV were included in the study. Out of these, 112 patients were from seven thalassemia centers in Tehran, Zafar adult thalassemia clinic, Childrens' medical center , Sodeh clinic, Aliasghar Hospital, Mofid Hospital, Special Medical center, Boali Hospital and from Shahid Bahonar hospital in Karaj City. The other 105 patients were from Amol thalassemia center at Imam Reza hospital in northern Iran. All staff members in Amol and Zafar adult thalassemia centers were anti-HCV negative. Table 1 indicates the patients` information, age and gender. The patients received blood transfusions, every two to four weeks and had been regularly tested for anti-HCV every six months or once a year at least since 2001. Information was obtained by a questionnaire on date of birth, gender, age at first transfusion, duration of transfusion therapy, number of transfusions received until the time of sampling, risk factors, and date of admission to the thalassemia center. Retrospectively, further interviews were conducted in 2008 on 36 patients found infected with similar HCV strains. The purpose of the study was explained to the patients or to the parents of the children and informed consent was obtained before sampling. This study was conducted in compliance with the World Medical Association Declaration of Helsinki and was approved by Tehran University of Medical Sciences Ethics Committee. All anti-HCV positive patients diagnosed as thalassemic were included in the study except those also seropositive for hepatitis B virus (HBV) or immunodeficiency virus (HIV). All the patients fromTehran and Amol were bled during 2006 and 2007, respectively.

Table 1. Characteristics of 217 Thalassemia Patients Transfused in Tehran and Amol and PCR and Sequencing Results of Their HCV Strains

\begin{tabular}{lllllllll}
\hline Region & No. & $\begin{array}{l}\text { Males/Fe- } \\
\text { males }\end{array}$ & $\begin{array}{l}\text { Age, } \mathbf{y}, \\
(\text { min-max })\end{array}$ & Mean \pm SD & \multicolumn{2}{c}{ HCV PCR Positive } & \multicolumn{2}{c}{ No. of Sequenced Strains } \\
\cline { 6 - 9 } & & & & $\begin{array}{l}\text { NS5B, No. } \\
(\%)\end{array}$ & $\begin{array}{l}\text { Core, No. } \\
(\%)\end{array}$ & $\begin{array}{l}\text { NS5B, No. } \\
(\%)\end{array}$ & $\begin{array}{l}\text { Core, No. } \\
(\%)\end{array}$ \\
\hline Tehran & 112 & $56 / 56$ & $12-47$ & $25.2 \pm 7.0$ & $60(54)$ & $13(24)^{\mathrm{a}}$ & $58(97)$ & $11(85)^{\mathrm{a}}$ \\
\hline Amol & 105 & $56 / 49$ & $11-63$ & $21.5 \pm 7.4$ & $58(55)$ & $3(6)$ & $58(100)$ & $3(100)$ \\
Total & 217 & $112 / 105$ & $11-63$ & $23.4 \pm 7.4$ & $118(54)$ & $16(16)$ & $116(98)$ & $14(88)$ \\
\hline
\end{tabular}

$\mathrm{a}$ Including two samples which could be amplified but not sequenced based on NS5B region

\subsection{RNA Extraction and PCR}

$100 \mu \mathrm{l}$ plasma was added to $500 \mu \mathrm{l}$ lysis buffers (0.5\% SDS and $10 \mathrm{mM}$ EDTA) and $500 \mu \mathrm{l}$ water saturated phenol. RNA was precipitated with isopropanol. The pellet was washed with $70 \%$ ethanol and dissolved in $20 \mu$ distilled water. cDNA synthesis and semi-nested PCR were performed with primers hep101, hep102 and hep105 as previ- ously described $(7,8)$ to give a 380-bp product between positions 8258 and 8687 of NS5B. The 5'UTR- core region was also amplified for several strains using the primers 186/NCR3 and 186/univ-1 (8).

\subsection{Sequencing and Phylogenetic Analysis}

The products obtained from the NS5B and 5'UTR-core 
regions were purified using GFX PCR DNA and Gel band purification kit (GE Healthcare, Buckinghamsure, UK). The sequencing reaction was carried out with the ABI PRISM TM Big Dye TM Terminator Cycle Sequencing Reaction Kit (Applied Biosystem, Foster city, CA, USA, version 3.1) using purified PCR products as templates. PCR products amplified within the NS5B region were sequenced with hep105, and those amplified within the 5'UTR-core region were sequenced with primers univ-1 and 186. The obtained sequences were aligned with 347 sequences of the corresponding region retrieved from Gen Bank (see accession numbers in Figure 1). The genetic distances between the aligned sequences were calculated using the F84 model in DNADIST in the Phylip program package version 3.66c. Phylogenetic trees were constructed using the UPGMA algorithm in the program NEIGHBOUR in the Phylip program package. The sequences obtained in this work are deposited in GenBank with accession numbers KC118130- KC118333.

\subsection{Statistical Analysis}

Statistical analysis was performed with Fisher's test. $\mathrm{P}<$ 0.05 was considered statistically significant.

\section{Results}

Most of the patients had been hepatitis $C$ infected before 1996, when testing for anti-HCV and blood screening was introduced in Iran. However, 34 (16\%) patients had been infected after 1996, most of them, 26 (76\%), were infected after 2000 (Table 2). Fourteen of these patients were from Tehran and 20 from Amol. The thalassemia centers have separate transfusion rooms for men and women, and several patients are simultaneously transfused at the same shift in the same room. HCV RNA was detected in sera from $132(61 \%)$ patients. The subtype could be determined in 130 of them, 69 from Tehran and 61 from Amol (Table 1). The NS5B region was amplified and sequenced for 116 strains and the core region only for 14 strains (Table 1). The most common subtype found from the Tehran centers was 1a in 34 (49\%) patients followed by 1 b in 17 (25\%) and $3 \mathrm{a}$ in 15 ( $22 \%)$. Strains of subtypes $2 \mathrm{k}$, 3k, and $4 \mathrm{a}$ were found infecting one patient each (Table 3). Patients at the center in Amol were also mainly infected by 1a strains (n $=35 ; 57 \%$ ), whereas $1 \mathrm{~b}$ was found only in two, which was significantly less thanthat of Tehran $(\mathrm{P}<0.001)$. Subtype 3a was somewhat more frequent in Amol compared to Tehran, 39 \% versus $22 \%$ (Table 3 ). In the NS5B region, there were significantly more similar 1a strains, diverging with less than six nucleotides from each other, in Amol center than in Tehran centers, 24/35; 69 \% versus $6 / 34 ; 18 \%$ (P $\leq$ $0.001)$. Phylogenetic analysis of the NS5B region revealed high divergence between the strains. However, strains from 57 patients diverged with less than six nucleotides from strains of at least one other patient, and formed 19 clades (Figure 1a-d). Seventeen (89\%) of these clades were formed by strains from patients of the same sex (Table 4). The majority of the patients with similar strains, 47 (82 $\%$ ), had been infected before 1996. The strains from the 10 patients infected after 1996 were found in eight of the 19 clades. They did not form separate clades, and were mostly similar to strains from patients infected before 1996 (Table 4). Clades one to 12 were formed by 33 (52.3\%) of the 65 subtype 1a strains in this study (Figure 1a-b, Table 4). Four of these (clades 2, 4, 9, and 11) were formed exclusively by strains from Tehran patients. The patients infected with strains in three of these clades (4, 9 and 11) had frequently been transfused in the same room at the same shift (Table 4).

Table 2. Years of Start of Transfusion and of Seroconversion to anti-HCV in 34 Thalassemia Patients Infected After 1996 in Tehran and Amol

\begin{tabular}{|c|c|c|c|c|c|c|c|}
\hline \multirow[t]{2}{*}{ Region } & \multirow[t]{2}{*}{$\begin{array}{l}\text { Total, No. of } \\
\text { Patients }\end{array}$} & \multirow{2}{*}{$\begin{array}{l}\text { Cases In- } \\
\text { fected After } \\
\text { 1996, No. (\%) }\end{array}$} & \multicolumn{2}{|c|}{ Start of Transfusion } & \multicolumn{2}{|c|}{$\begin{array}{c}\text { Year of Seroconversion to } \\
\text { anti-HCV }\end{array}$} & \multirow{2}{*}{$\begin{array}{l}\text { HCV RNA } \\
\text { Positve, No. } \\
\text { (\%) }\end{array}$} \\
\hline & & & $\begin{array}{l}\text { Before 1996, } \\
\text { No. (\%) }\end{array}$ & $\begin{array}{l}\text { After1996, } \\
\text { No. }(\%)\end{array}$ & $\begin{array}{l}\text { 1996-2000, } \\
\text { No. }(\%)\end{array}$ & $\begin{array}{l}\text { 2001-2006, } \\
\text { No. }(\%)\end{array}$ & \\
\hline Tehran & 112 & $14(12.5)$ & $13(93)$ & $1(7)$ & $3(21)$ & $11(79)$ & $6(43)$ \\
\hline Amol & 105 & $20(19)$ & $15(75)$ & $5(25)$ & $5(25)$ & $15(75)$ & $10(50)$ \\
\hline Total & 217 & $34(16)$ & $28(82)$ & $6(18)$ & $8(24)$ & $26(76)$ & $16(47)$ \\
\hline
\end{tabular}

Table 3. Results from Genotyping 130 HCV Strains from Tehran and Amol

\begin{tabular}{llllllll}
\hline Region & \multirow{2}{*}{$\begin{array}{l}\text { No. of geno- } \\
\text { typedstrains }\end{array}$} & \multicolumn{7}{c}{ Genotype } \\
\cline { 3 - 8 } & $\mathbf{1 a}$, No. $(\%)$ & $\mathbf{1 b}$, No. $(\%)$ & $\mathbf{2 k}$, No. (\%) & 3a, No. (\%) & 3k, No. (\%) & 4a, No. (\%) \\
\hline Tehran & 69 & $34(49.3)^{\mathrm{a}}$ & $17(24.7)^{\mathrm{b}}$ & $1(1.4)$ & $15(21.8)$ & $1(1.4)^{\mathrm{c}}$ & $1(1.4)$ \\
\hline Amol & 61 & $35(57.4)^{\mathrm{c}}$ & $2(3.3)$ & 0 & $24(39.3)^{\mathrm{d}}$ & 0 & 0 \\
\hline Total & 130 & $69(53)$ & $19(14.6)$ & $1(0.8)$ & $39(30)$ & $1(0.8)$ & $1(0.8)$ \\
\hline
\end{tabular}

Number of strains typed only by sequencing of the core region:

$\mathrm{a}_{4 \text { strains; }}{ }^{\mathrm{b}} 7$ strains; ${ }^{\mathrm{c}} 1$ strain; ${ }^{\mathrm{d}}{ }_{2}$ strains 


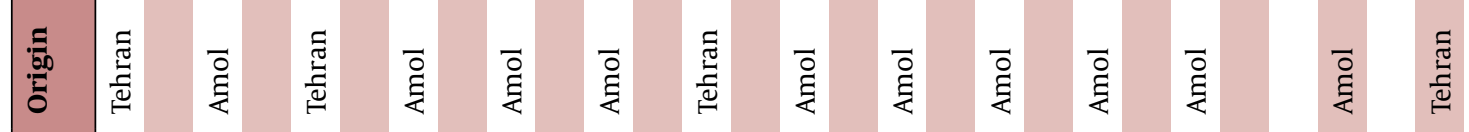

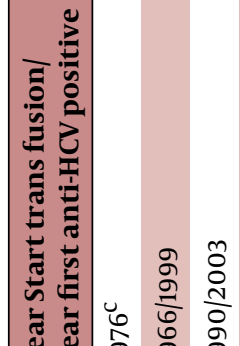

ư

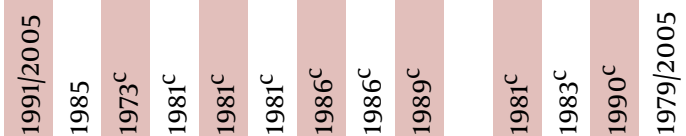

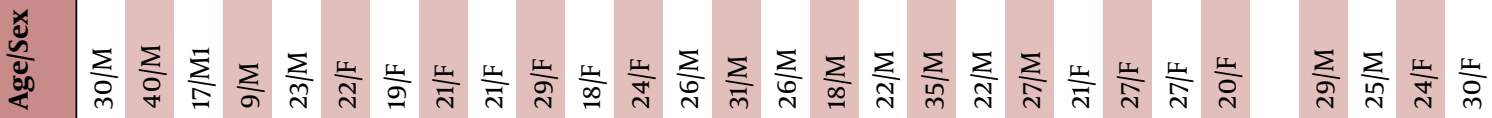

\section{艺}

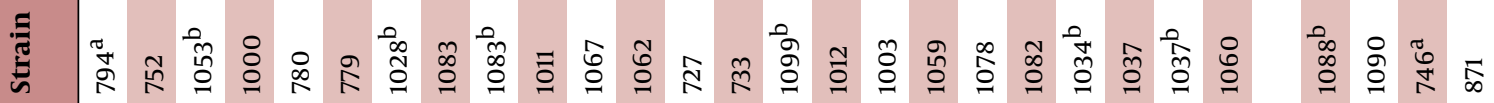

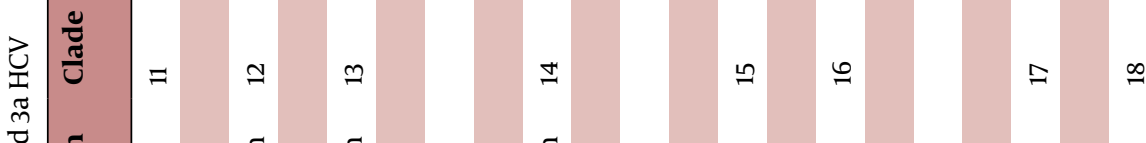

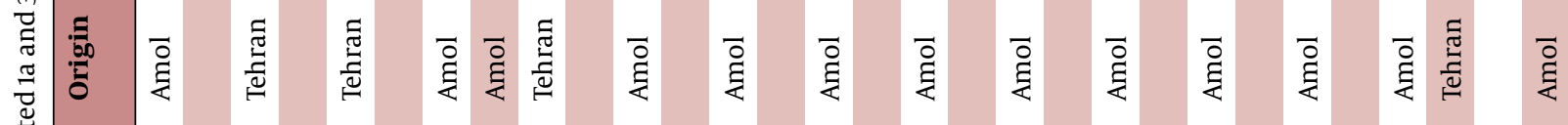

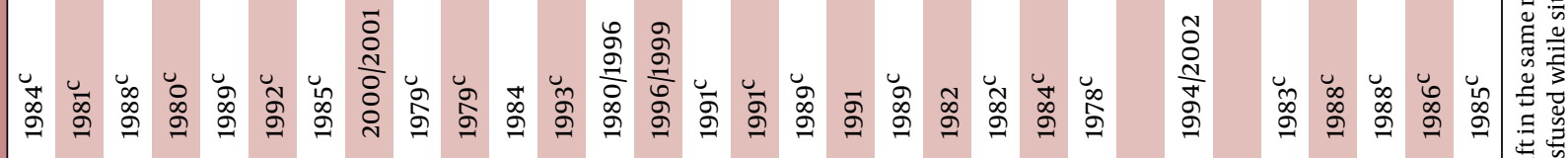

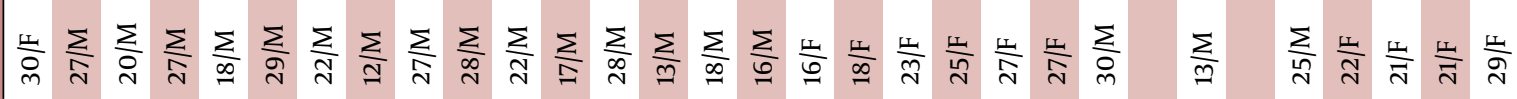

\section{:}

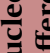

$\rightarrow \quad r \quad m \quad$ \&

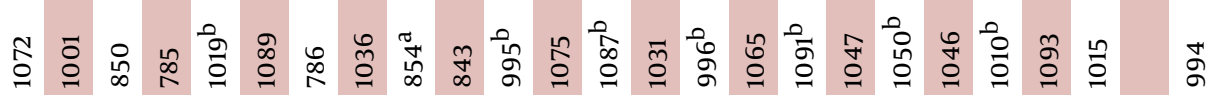

苟 岂

ฮั
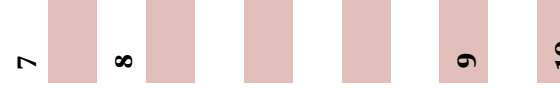

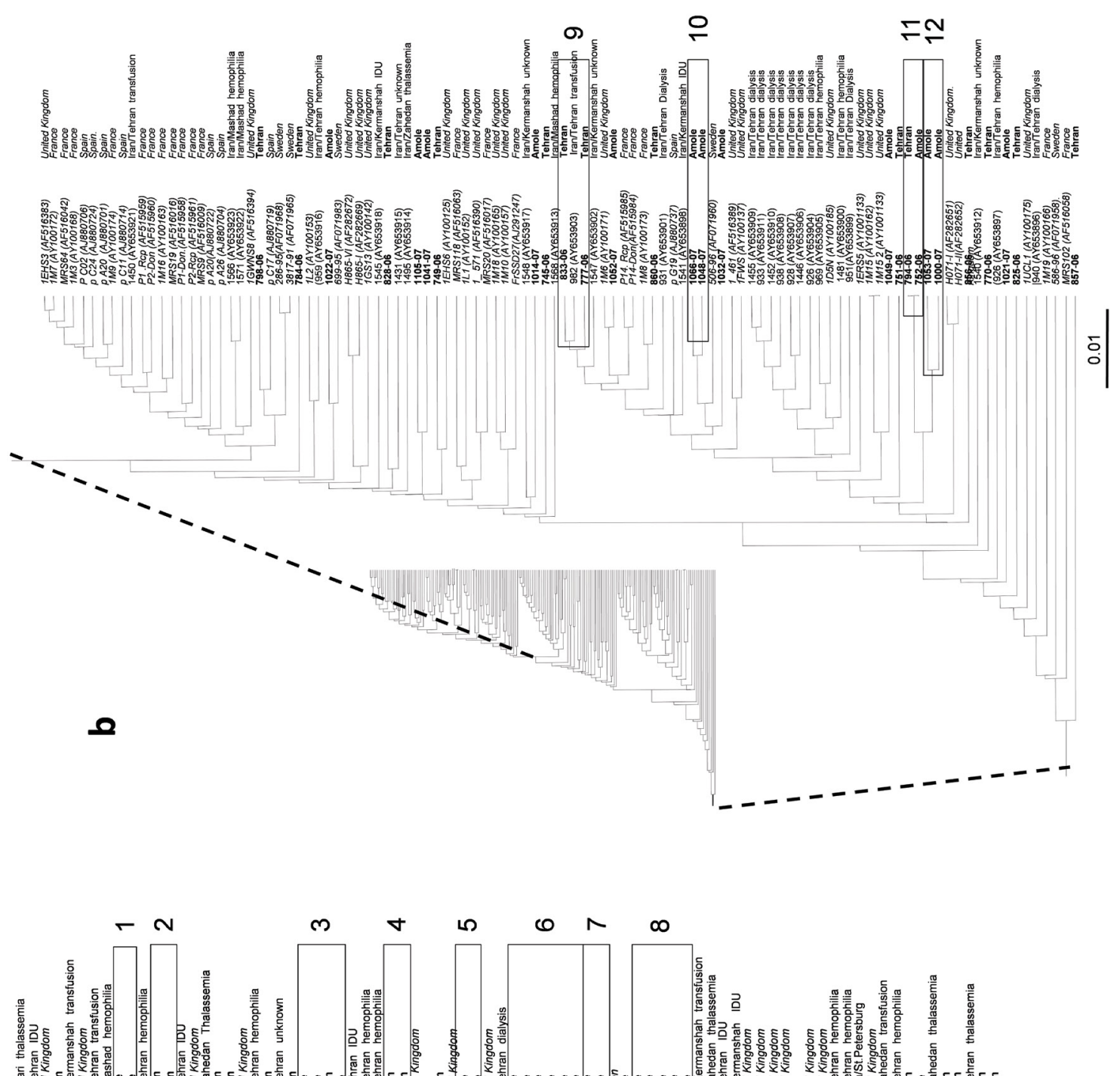

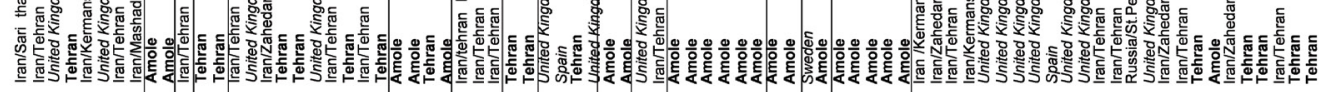

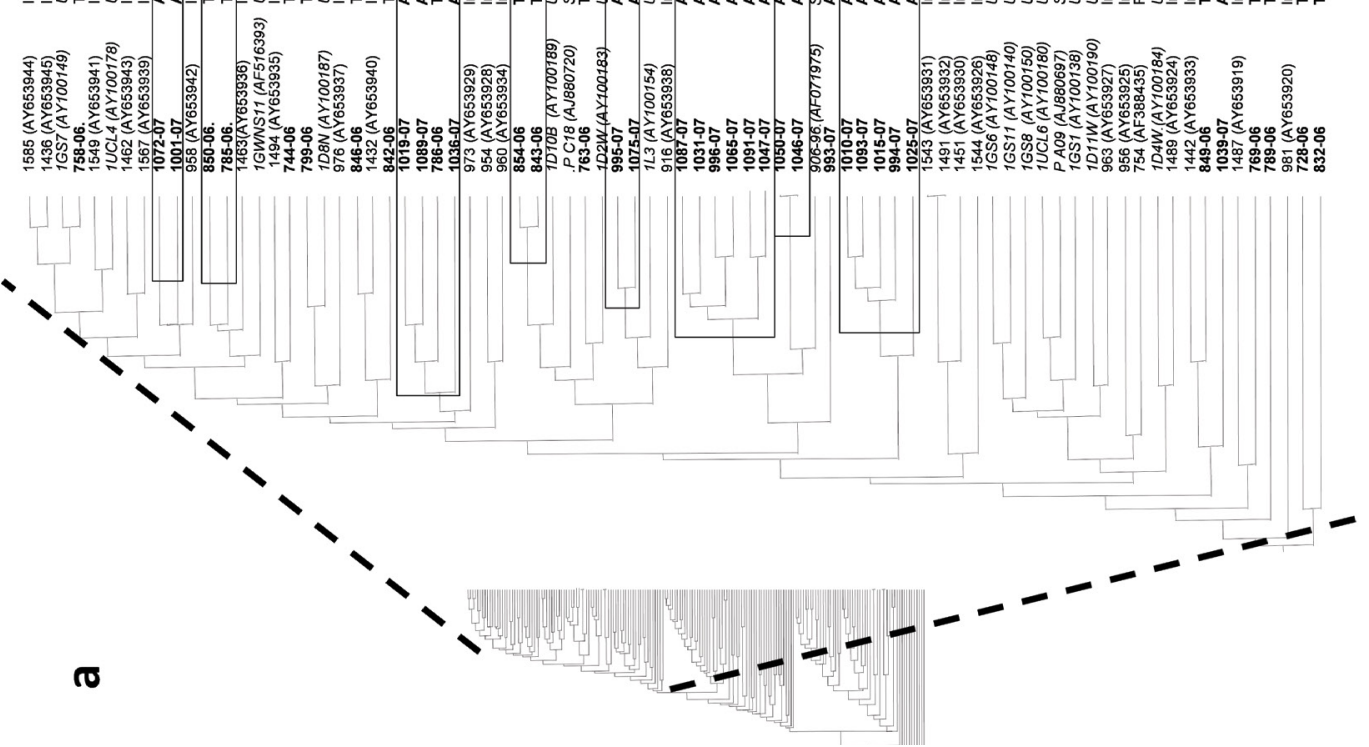




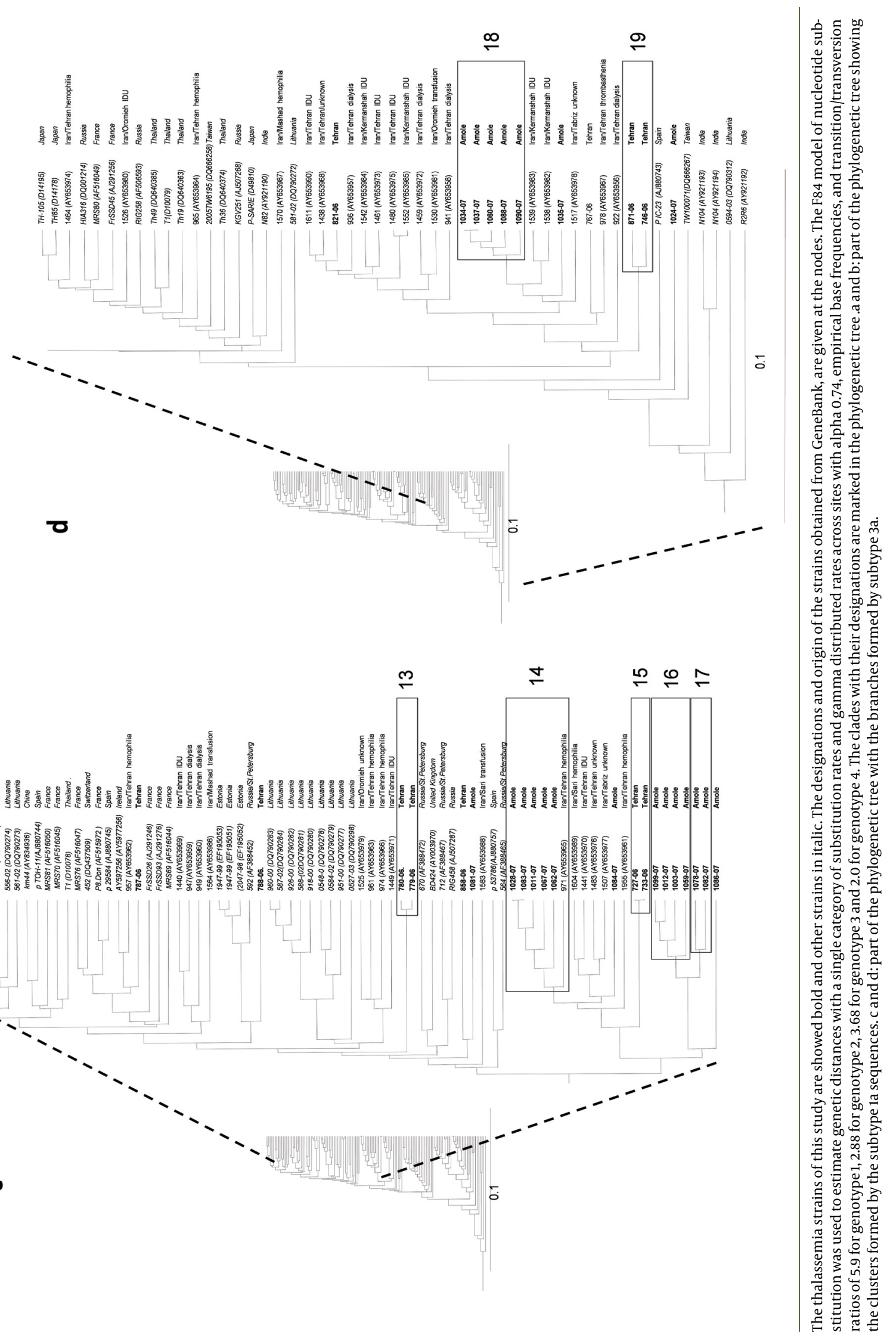


Strain 752 in clade 11 was from a patient infected in 1999 and identical to strain 794 from a patient infected before 1996. Seven clades were formed by strains only from Amol (clades 1, 5, 6, 7, 8, 10 and 12; Figure 1a-b). An additional clade, 3, was formed by strains mainly from Amol, but also with one strain from Tehran. Strains in six of these 1a clades were from 16 patients (eight pairs) who had been transfused simultaneously sitting on the same bed at the center in Amol (Table 4). Two of the eight pairs were formed by one patient each infected before and after 1996 . Seven clades were formed by 22 of the 37 (59\%) subtype 3a strains in the current study study (Figure 1c-d). Three clades were formed by strains from Tehran (clades 13,15 and 19) and four by strains from Amol (clades 14,16, 17 and 18; Table 4; Figure $1 c$-d). There were significantly more closely related 3a strains among patients from Amol as compared to those of Tehran, $73 \%$ versus $40 \%$, respectively ( $\mathrm{P}<0.001)$. Strains in three of these clades $(14,16$ and 18$)$ were from 12 patients (six pairs) who had been transfused at the same shift sitting next to each other on the same bed in Amol. Two patients with strains in clade 14 and one patient with a strain in clade 16 had been infected between 1999 and 2005, while the other patient in the pairs had been infected before 1996. Clade 19 was formed by two strains from patients who had frequently been transfused at the same shift in the same room in a center in Tehran (Table 4; Figure 1c-d). One of the male patients in this clade had been infected in 2005. The 12 subtype 1b strains all diverged with more than five nucleotides from each other and did not form any clades, but were interdispersed among1b strains derived world-wide. This was significantly different as compared to the other subtypes $(\mathrm{P}<0.001)$ when all strains were considered. However, most of the $1 \mathrm{~b}$ strains, 10 , were from Tehran centers, which generally had fewer similar strains circulating than the center in $\operatorname{Amol}(\mathrm{P}=0.015)$. When only the strains from Tehran centers were considered, the lack of similar $1 \mathrm{~b}$ strains as compared to strains belonging to other subtypes was less significant ( 0 versus $15 ; \mathrm{P}=0.05$ ). The patient infected with the $4 \mathrm{a}$ strain had been transfused for 8 years in the United Arab Emirates, and had probably been infected there.

\section{Discussion}

The frequencies of subtype $1 \mathrm{~b}$ and $3 \mathrm{a}$ in hepatitis $\mathrm{C}$ infected thalassemia patients from Tehran were $25 \%$ and $22 \%$, respectively, which were in contrast with the findings from the thalassemia centers in Amol, where 1a and 3a were the most prevalent subtypes. In addition, data from earlier Iranian studies showed subtypes 1a and 3a were the most common ones in the country with geographical differences in their distribution, and 1a was frequent among patients infected through blood transfusion (9-11). Several factors may be responsible for the introduction of various subtypes and strains that may infect patients at the thalassemia centers in Tehran. First,
$25 \%$ of the hepatitis C infected patients had been treated in other cities or abroad for several years before starting treatment in Tehran, such as the patient infected with $4 \mathrm{a}$, who had been treated in the United Arab Emirates $(12,13)$. Second, due to a high demand for blood in Tehran, it is unavoidable for the centers to use blood supplied from other Iranian cities, which might result the introduction of various HCV subtypes. Third, sampling in Tehran was done at several thalassemia centers which may differ with regard to the number of patients, amount of blood provided from the other parts of Iran, rate of HCV infections and number of patients previously transfused in other cities or abroad. The number of new HCV infected patients decreased when blood screening for anti-HCV was introduced in Iran in 1996, the current study also indicated that $86 \%$ of the patients had been infected before 1996. However, 34 (16\%) of the patients had become hepatitis $C$ infected after 1996. Most of them had been infected in 2001 or later, and only eight had been infected between 1996 and 2000. This might have been an under-estimate, since there was no testing for anti$\mathrm{HCV}$ in thalassemia centers on a regular basis these years. Most patients from Tehran have been tested for anti-HCV since 1998, while there was no routinely anti HCV testing in Amol until 1999 or 2000. Phylogenetic analysis of the NS5B region revealed a high genetic variability of the strains at different centers. Although $54 \%$ of the 1a and 3a strains formed clades of similar strains, the strains from one clade were highly divergent from strains of the same subtype forming another clade. The variability between the strains and the clades may be due to several factors including transfusion of unscreened blood before 1996, blood obtained from other cities particularly for patients from Tehran, and the fact that $24 \%$ of the thalassemia patients had started their treatment in other cities. All these circumstances could lead to multiple entries of $\mathrm{HCV}$ lineages into the centers. However, in different centers there were closely related strains forming clades. Further epidemiological investigations revealed that 36 of these strains were isolated from patients frequently transfused at the same shift in the same room. Moreover, the number of related 1a and 3a strains from Amol was higher and these strains formed larger clades than the ones from Tehran. In addition, $71 \%$ of the patients infected with similar strains from Amol had been transfused while sitting next to each other on the same bed. This indicates that nosocomial transmission was more common in Amol thalassemia center than in those of Tehran. This could be due to Amol Thalassemia center was the only center in the city, and the number of patients often exceeded the number of beds, which could influence the patientto-patient transmission of hepatitis $\mathrm{C}$. The circulation of few similar strains, as in Amol, may also facilitate the identification of nosocomial transmission. The patients in Tehran were transfused at several centers, and could have been exposed to more divergent HCV strains. Some of the patients were also transfused and infected abroad, 
as the patient infected with $4 \mathrm{a}$ and probably the majority of those infected with $1 \mathrm{~b}$ strains. These $1 \mathrm{~b}$ strains were less related to each other and more similar to the strains from Western Europe (14), while the 1a and 3a strains were more similar to strains from other Iranian high risk groups. This suggests multiple entries of $1 \mathrm{~b}$ strains from abroad into the thalassemia centers in Tehran. The high similarity of the majority of the 1a and 3a strains suggests nosocomial transmission of HCV at the thalassemia centers. In a study on five new hepatitis $C$ cases infected at Zafar adult thalassemia clinic in 2004, all the blood donors whom could be traced, $69 \%$, were anti-HCV negative indicating patient-to patient transmission, although it was not shown by sequencing and genetic analysis of the patient strains (15). Nosocomial transmission of hepatitis $C$ has previously been described between patients and at different hospital settings outside Iran $(8,16-21)$. However, phylogenetic analysis of the HCV strains was performed only in few of the studies to identify common source of infection or route of transmission $(8,18,19)$. Until now, nosocomial HCV transmission based on sequencing and phylogenetic analysis of patient HCV strains at thalassemia centers has not previously been reported. The genetic analysis of the infecting strains in combination with further epidemiological analysis clearly indicated patient-to patient transmission of hepatitis $\mathrm{C}$ at the centers under study. More transmission events may have occurred than those identified, since some patients may have moved to other thalassemia centers or have died. Also, if the transmission occurred a long time ago, the strains may have diverged beyond a detectable association of the strains due to genetic drift. The exact mode of infection was not investigated, although the most likely factors may be the use of contaminated medical equipment or other poor enforcement of safety guidelines. Violation of safety procedures resulting in the spread of hepatitis $\mathrm{C}$ in hospitals has previously been documented $(16,22)$. The present study supports that nosocomial transmission plays a possible role in HCV spread at Iranian thalassemia centers. Education of staff and implementation of strict infection control practices are thus necessary in order to reduce the number of new cases of hepatitis $C$ at these centers.

\section{Acknowledgements}

The authors gratefully acknowledge their gratitude to Dr.Bashir Hajibeigy (Research Center of Iranian Blood Transfusion Organization, Tehran, Iran), the staff and the patients of the thalassemia centers for their excellent cooperation in data and sample collection.

\section{Authors' Contribution}

KS and $\mathrm{HN}$ were responsible for the conception, design and analysis of the study. KS collected the samples, performed the experiments and wrote the draft of the paper. LM did the critical revision of the paper. HN, LM, SMA and
KS prepared the final version of the paper. FA carried out the statistical analysis. MN, AE, AA, SME, FZ and SMA provided the study subjects and data collection.

\section{Financial Disclosure}

None declared.

\section{Funding/Support}

This study was supported by the grant from the Swedish Research Links 348-2005-6250 and from the Swedish Research Council VR521-2006-2753.

\section{References}

1. Rezvan H, Abolghassemi H, Kafiabad SA. Transfusion-transmitted infections among multitransfused patients in Iran: a review. Transfus Med.2007;17(6):425-33.

2. Abolghasemi H, Amid A, Zeinali S, Radfar MH, Eshghi P, Rahiminejad MS, et al. Thalassemia in Iran: epidemiology, prevention, and management. J Pediatr Hematol Oncol.2007;29(4):233-8.

3. Alavian S, Tabatabaei S, Lankarani K. Epidemiology of HCV infection among thalassemia patients in eastern Mediterranean countries: a quantitative review of literature. Iranian Red Crescent Medical Journal.2010;12(4):365-76.

4. Merat S, Rezvan H, Nouraie M, Jafari E, Abolghasemi H, Radmard AR. Seroprevalence of hepatitis C virus: the first populationbased study from Iran. Int J Infect Dis.2010;14 Suppl 3:e113-6.

5. Samimi-Rad K, Hosseini M, Mobeini G, Asgari F, Alavian SM, Tahaei ME, et al. Hepatitis $C$ virus infection among multi-transfused patients and personnel in haemodialysis units in central Islamic Republic of Iran. East Mediterr Health J.2012;18(3):227-35.

6. Mirmomen S, Alavian SM, Hajarizadeh B, Kafaee J, Yektaparast B, Zahedi MJ. Epidemiology of hepatitis B, hepatitis C, and human immunodeficiency virus infecions in patients with beta-thalassemia in Iran: a multicenter study. Arch Iran Med.2006;9(4):31923.

7. Kalinina O, Norder H, Vetrov T, Zhdanov K, Barzunova M, Plotnikova $\mathrm{V}$, et al. Shift in predominating subtype of HCV from $1 \mathrm{~b}$ to 3a in St. Petersburg mediated by increase in injecting drug use. Med Virol.2001;65(3):517-24.

8. Norder H, Bergstrom A, Uhnoo I, Alden J, Weiss L, Czajkowski J, et al. Confirmation of nosocomial transmission of hepatitis $C$ virus by phylogenetic analysis of the NS5-B region. J Clin Microbiol.1998;36(10):3066-9.

9. Samimi-Rad K, Shahbaz B. Hepatitis C virus genotypes among patients with thalassemia and inherited bleeding disorders in Markazi province, Iran. Haemophilia.2007;13(2):156-63.

10. Samimi-Rad K, Nategh R, Malekzadeh R, Norder H, Magnius L. Molecular epidemiology of hepatitis $\mathrm{C}$ virus in Iran as reflected by phylogenetic analysis of the NS5B region. $J$ Med $\mathrm{Vi}$ rol.2004;74(2):246-52.

11. Alavian SM, Miri SM, Keshvari M, Elizee PK, Behnava B, Tabatabaei SV, et al. Distribution of hepatitis C virus genotype in Iranian multiply transfused patients with thalassemia. Transfusion.2009;49(10):2195-9.

12. Shobokshi OA, Serebour FE, Skakni LI. Hepatitis C genotypes/subtypes among chronic hepatitis patients in Saudi Arabia. Saudi Med J.2003;24 Suppl 2:S87-91.

13. Chamberlain RW, Adams N, Saeed AA, Simmonds P, Elliott RM Complete nucleotide sequence of a type 4 hepatitis $\mathrm{C}$ virus variant, the predominant genotype in the Middle East. $J$ Gen Virol.1997;78(Pt 6):1341-7.

14. Simmonds P. The origin and evolution of hepatitis viruses in humans. J Gen Virol.2001;82(Pt 4):693-712.

15. Azar KA, Hajibeygi B, Nasiri TM, Amini Kafiabad S, Maghsoudlou M, Shadman AH. Blood (Khoon).2010;7(3):156-61.

16. Krause G, Trepka MJ, Whisenhunt RS, Katz D, Nainan O, Wiersma 
ST, et al. Nosocomial transmission of hepatitis $\mathrm{C}$ virus associated with the use of multidose saline vials. Infect Control Hosp Epidemiol.2003;24(2):122-7.

17. Januszkiewicz-Lewandowska D, Wysocki J, Rembowska J, Pernak M, Lewandowski K, Nowak T, et al. Transmission of HCV infection among long-term hospitalized onco-haematological patients. J Hosp Infect.2003;53(2):120-3.

18. Gonzalez-Candelas F, Guiral S, Carbo R, Valero A, Vanaclocha H, Gonzalez F, et al. Patient-to-patient transmission of hepatitis C virus (HCV) during colonoscopy diagnosis. Virol J.2010;7:217.

19. Dencs A, Hettmann A, Martyin T, Jekkel C, Banyai T, Takacs M. Phylogenetic investigation of nosocomial transmission of hepatitis
C virus in an oncology ward. J Med Virol.2011;83(3):428-36.

20. Comstock RD, Mallonee S, Fox JL, Moolenaar RL, Vogt TM, Perz JF, et al. A large nosocomial outbreak of hepatitis $C$ and hepatitis $\mathrm{B}$ among patients receiving pain remediation treatments. Infect Control Hosp Epidemiol.2004;25(7):576-83.

21. Bronowicki JP, Venard V, Botte C, Monhoven N, Gastin I, Chone L, et al. Patient-to-patient transmission of hepatitis $\mathrm{C}$ virus during colonoscopy. N EnglJ Med.1997;337(4):237-40.

22. PerZ JF, Thompson ND, Schaefer MK, Patel PR. US outbreak investigations highlight the need for safe injection practices and basic infection control. Clin Liver Dis.2010;14(1):137-51. x. 